RODRIGO GARLA JORGE

\title{
DISPENSA DE LICITAÇÃO FUNDAMENTADA EM SITUAÇÕES EMERGENCIAIS OU DE CALAMIDADE PÚBLICA
}

\author{
Dissertação de Mestrado \\ Orientador: Professor Dr. Edmir Netto de Araújo
}

UNIVERSIDADE DE SÃO PAULO

FACULDADE DE DIREITO

São Paulo - SP

2019 


\title{
DISPENSA DE LICITAÇÃO FUNDAMENTADA EM SITUAÇÕES EMERGENCIAIS OU DE CALAMIDADE PÚBLICA
}

\begin{abstract}
Dissertação apresentada à Banca Examinadora do Programa de Pós-Graduação em Direito, da Faculdade de Direito da Universidade de São Paulo, como exigência parcial para obtenção do título de Mestre em Direito, na área de concentração Direito do Estado, sob orientação do Professor Dr. Edmir Netto de Araújo.
\end{abstract}

\section{UNIVERSIDADE DE SÃO PAULO \\ FACULDADE DE DIREITO \\ São Paulo - SP




\section{Catalogação na Publicação}

Serviço de Processos Técnicos da Biblioteca da

Faculdade de Direito da Universidade de São Paulo

Jorge, Rodrigo Garla.

Dispensa de licitação fundamentada em situações emergenciais ou de calamidade pública / Rodrigo Garla Jorge. -- São Paulo, 2019.

158 p. ; $30 \mathrm{~cm}$.

Dissertação (Mestrado) - Programa de Pós-Graduação em Direito,

Faculdade de Direito, Universidade de São Paulo, São Paulo, 2019.

Orientador: Edmir Netto de Araújo.

Notas de rodapé

Inclui bibliografia

1. Dispensa de licitação fundamentada em situações emergenciais ou de calamidade pública. 2. Artigo 24, inciso IV, da Lei 8.666/1993. 3. Pressupostos de validade da contratação. 4. Limites contratuais. 5. Flexibilização procedimental. 6. Superações legais. I. Araújo, Edmir Netto de, orient. II. Título. 


\section{DEDICATÓRIA}

À minha esposa, Giovana, fonte eterna de amor, inspiração e apoio. 


\section{AGRADECIMENTOS}

A Deus, Senhor da minha vida, responsável por todas as vitórias obtidas e titular das respectivas glórias.

Ao meu amado pai, Dorival, cuja saudade corta profundamente o meu coração por todos os dias, e à minha querida mãe, Deise, referências eternas da minha vida, por todo amor que sempre me proporcionaram. Sem vocês, nada faria sentido.

Aos meus irmãos, Renata e Renan, pela amizade incondicional que tudo suporta e nada se pretende.

Ao meu orientador e verdadeiro amigo, Prof. Edmir Netto de Araújo, exemplo não só de dedicação à atividade acadêmica e profissional como também de ser humano, pela oportunidade e pelos ensinamentos que me foram conferidos. 


\section{RESUMO}

JORGE, Rodrigo Garla. Dispensa de licitação fundamentada em situações emergenciais ou de calamidade pública. 2019. 158 f. Mestrado - Faculdade de Direito, Universidade de São Paulo, 2019.

O presente trabalho tem por escopo principal examinar a hipótese de dispensa de licitação fundamentada em situações emergenciais ou de calamidade pública prevista no artigo 24, inciso IV, da Lei $\mathrm{n}^{\mathrm{o}}$ 8.666/1993, a fim de definir, de modo objetivo e fundamentado com base na doutrina especializada e na jurisprudência técnico-administrativa do Tribunal de Contas da União, os critérios legitimadores de sua interpretação e aplicação, bem como fixar os seus limites e as respectivas superações legais. Para tanto, em um primeiro momento, serão abordados os aspectos gerais e fundamentais do instituto da licitação. Na sequência, a análise dirigir-se-á às contratações diretas, sem a realização do procedimento ordinário de licitação. A partir de então, adentrar-se-á ao ponto fulcral da pesquisa, oportunidade em que se investigará especificamente a regra decorrente do dispositivo acima citado. Nesta ocasião, serão examinados os pressupostos de validade da contratação, os seus limites contratuais e a possibilidade da flexibilização de seu procedimento. A parte final do trabalho será destinada a relacionar as superações legais apresentadas no curso da pesquisa com princípios legitimadores de sua intepretação e aplicação, com especial atenção para os princípios da legalidade, finalidade, obrigatoriedade de desempenho da atividade pública, eficiência e razoabilidade.

Palavras-chave: Dispensa de licitação fundamentada em situações emergenciais ou de calamidade pública. Artigo 24, inciso IV, da Lei 8.666/1993. Pressupostos de validade da contratação. Limites contratuais. Flexibilização procedimental. Superações legais. 


\begin{abstract}
JORGE, Rodrigo Garla. Exemption of bidding based on emergency situations or public calamity. 2019. 158 p. Master - Faculty of Law, University of São Paulo, 2019.

The main purpose of this paper is to examine the hypothesis of exemption of bidding based on emergency situations or public calamity, provided for in article 24 , subsection IV, of Law $n^{\circ}$ $8.666 / 1993$, in order to define, objectively and grounded on the specialized doctrine and the technical-administrative jurisprudence of the Federal Court of Auditors, the legitimating criteria to its interpretation and application, as well as to establish its limits and legal overcoming. In order to do that, at first, it will be approached the general and fundamental aspects of the bidding institute. Subsequently, the analysis will be targeted to direct contracting, without the ordinary bidding procedure. After that, it will be introduced the key point of the research, at which time will be specifically investigated the rule resulting from the previous article. On this occasion, will examinated the premises about the validity of the contract, its limits and the possibility of bending the procedure rules. The final part of the essay will be aimed at relating the legal overcomes presented in the course of the research with legitimating principles of its interpretation and application, with special attention regarding the principles of rule of law, purpose, obligation of public activity performance, efficiency and reasonableness.
\end{abstract}

Keywords: Exemption of bidding based on emergency situations or public calamity. Article 24, subsection IV, of Law $n^{0} 8.666 / 1993$. Premises about the validity of the contract. Contractual limits. Bending procedure rules. Legal overcoming. 


\section{SUMÁRIO}

1 - INTRODUÇÃO

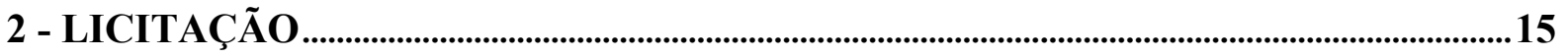

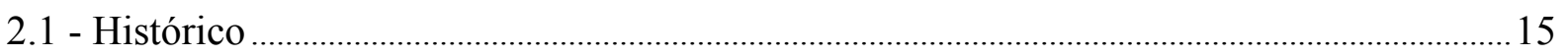

2.2 - Natureza jurídica ……………………………………………………………………... 19

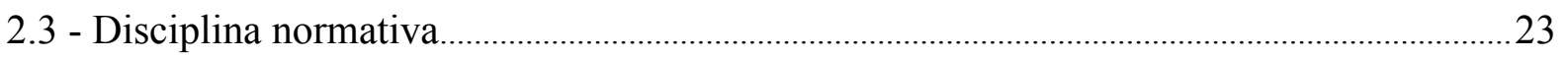

2.4 - Finalidades, fundamentos e pressupostos .................................................................................29

2.5 - A Licitação como um Princípio Constitucional ………………………………………………..... 32

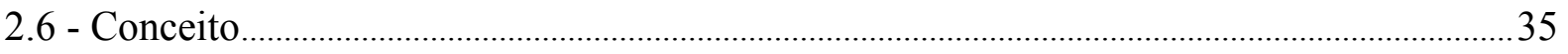

3 - CONTRATAÇÕES DIRETAS ...........................................................................................39

3.1 - Noções Gerais ....……………………………………………………………………………... 39

3.2 - Inexigibilidade de Licitação ……………………………………………………………...42

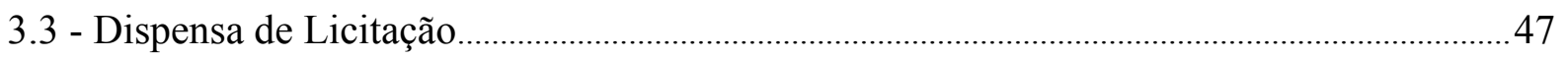

3.3.1 - Licitação Dispensada ............................................................................................49

3.3.2 - Licitação Dispensável .............................................................................................53

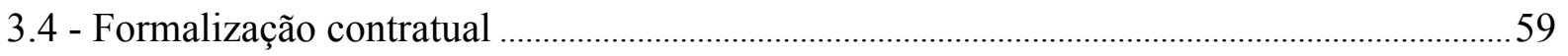

4 - DISPENSA DE LICITAÇÃO FUNDAMENTADA EM SITUAÇÕES EMERGENCIAIS OU DE CALAMIDADE PÚBLICA.........................................................65

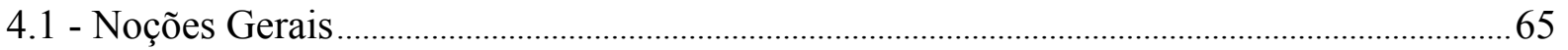

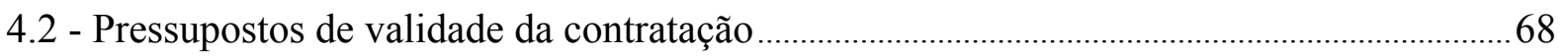

4.2.1 - Conceito de "Calamidade Pública".................................................................................72

4.2.2 - Conceito de "Emergência" ........................................................................................ 76

4.2.2.1 - "Emergência Fabricada" e suas consequências .....................................................80

4.2.2.2 - Emergência e a situação causada por obstrução judicial.....................................85

4.2.2.3 - Emergência e a situação causada pelo contingenciamento de repasses de

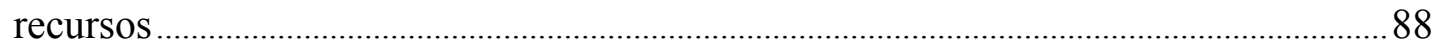

4.2.3 - Urgência de atendimento a um risco iminente de dano ..............................................91 
4.2 .4 - Objeto contratual adequado ………………………………………………………... 95

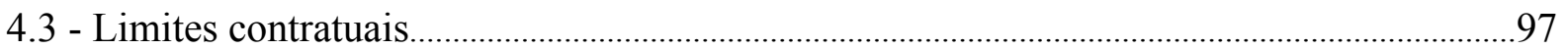

4.3.1 - Limites ao objeto contratual ....................................................................................99

4.3.2 - Limites à vigência do contrato............................................................................................104

4.4 - Flexibilização Procedimental..........................................................................................................111

4.4.1 - Projeto básico simplificado...............................................................................................115

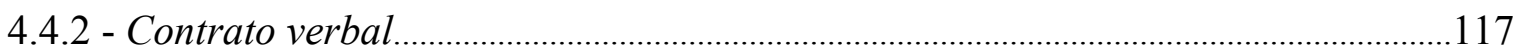

\section{5 - SUPERAÇÕES LEGAIS A PARTIR DE UMA ANÁLISE} PRINCIPIOLÓGICA...................................................................................................................120

5.1 - Aspectos introdutórios.......................................................................................................120

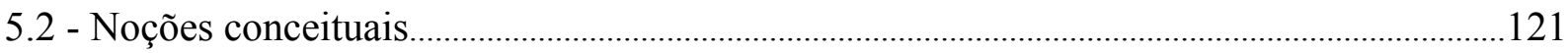

5.3 - Princípio da Legalidade ..........................................................................................................125

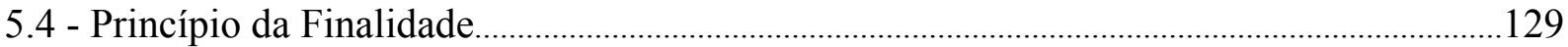

5.5 - Princípio da Obrigatoriedade do Desempenho da Atividade Pública....................................134

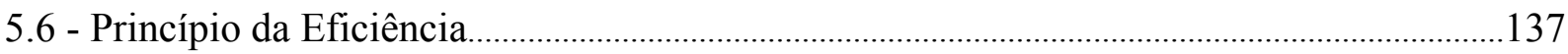

5.7 - Princípio da Razoabilidade ………………………………………………………………….....140

6 - CONCLUSÕES.........................................................................................................................146

7 - BIBLIOGRAFIA.......................................................................................................................151 


\section{1 - INTRODUÇÃO}

A República Federativa do Brasil constitui-se em Estado Democrático de Direito, fato este que impõe, dentre outras situações, a submissão não só dos respectivos cidadãos, mas também do próprio Estado às normas vigentes no ordenamento jurídico pátrio.

Esta constituição tem como um de seus alicerces o princípio da igualdade, direito fundamental de caráter individual que determina, em síntese, ao Estado, em suas relações, a necessidade de assegurar tratamento igual aos sujeitos que se encontrem nas mesmas condições.

No campo das contratações administrativas, o referido princípio é concretizado por meio da licitação, procedimento administrativo cuja previsão básica está no artigo 37, inciso XXI, da Constituição Federal de 1988 - CF/88, sendo dirigido diretamente ao Poder Público:

Art. 37. A administração pública direta e indireta de qualquer dos Poderes da União, dos Estados, do Distrito Federal e dos Municípios obedecerá aos princípios de legalidade, impessoalidade, moralidade, publicidade e eficiência e, também, ao seguinte:

$[\ldots]$

XXI - ressalvados os casos especificados na legislação, as obras, serviços, compras e alienações serão contratados mediante processo de licitação pública que assegure igualdade de condições a todos os concorrentes, com cláusulas que estabeleçam obrigações de pagamento, mantidas as condições efetivas da proposta, nos termos da lei, o qual somente permitirá as exigências de qualificação técnica e econômica indispensáveis à garantia do cumprimento das obrigações.

Da leitura do dispositivo, pode-se constatar que as obras, serviços, compras e alienações realizadas pela Administração Pública direta e indireta de qualquer dos Poderes da União, dos Estados, do Distrito Federal e dos Municípios devem ser contratadas, em regra, mediante "processo de licitação pública" que assegure igualdade de condições a todos os concorrentes, justamente em cumprimento ao princípio destacado alhures. É como expõe Celso Antônio Bandeira de Mello, que, no âmbito da definição do princípio em exame, 
destaca também a necessidade de ensejar oportunidade de disputa a quaisquer interessados:

O princípio da igualdade implica o dever não apenas de tratar isonomicamente todos os que afluírem ao certame, mas também o de ensejar oportunidade de disputá-lo a quaisquer interessados que desejando dele participar, podem oferecer as indispensáveis condições de garantia. É o que prevê o já referido art. $37, \mathrm{XXI}$, da $\mathrm{CF}^{1}$.

No intuito de concretizar a imposição em comento, com supedâneo no artigo 22, inciso XXVII, da $\mathrm{CF} / 88^{2}$, a União editou a Lei ${ }^{\circ} 8.666 / 1993$, norma que estabelece, para além de comandos normativos específicos, regras gerais sobre licitação aplicáveis a todos os entes estatais que compõem a federação brasileira.

Devem os entes públicos, deste modo, contratar mediante procedimento licitatório, de forma a possibilitar que todos os interessados ofereçam, em condições iguais, propostas tendentes a satisfazer a pretensão administrativa lançada em edital, a obter a proposta mais vantajosa e a promover o desenvolvimento nacional.

Esta é a regra que vigora no âmbito do sistema normativo pátrio, cujo fundamento advém diretamente da Constituição Federal.

Referida regra, contudo, possui exceções. Com fundamento no mesmo artigo 37, inciso XXI, da CF/88, a Lei $n^{\circ} 8.666 / 1993$ consagra em seu texto hipóteses em que a Administração Pública pode contratar diretamente com terceiros, sem a realização de prévio procedimento licitatório.

Dentre estes casos, encontram-se as situações nas quais a licitação é dispensável (também denominados como casos de "dispensabilidade de licitação"), ocasião em que a realização do procedimento licitatório é possível, mas a sua efetivação constitui, a princípio,

\footnotetext{
${ }^{1}$ MELLO, Celso Antônio Bandeira de. Curso de Direito Administrativo. 32 ed. São Paulo: Malheiros, 2015, p. 546-547.

${ }^{2}$ Art. 22. Compete privativamente à União legislar sobre:

$[\ldots]$

XXVII - normas gerais de licitação e contratação, em todas as modalidades, para as administrações públicas diretas, autárquicas e fundacionais da União, Estados, Distrito Federal e Municípios, obedecido o disposto no art. 37 , XXI, e para as empresas públicas e sociedades de economia mista, nos termos do art. $173, \S 1^{\circ}$, III;
} 
faculdade do Administrador a ser norteada pela promoção do interesse público.

Tais hipóteses estão elencadas no artigo 24 da Lei no 8.666/1993, em um rol taxativo que apresenta atualmente trinta e cinco hipóteses.

Em meio a estas situações, o inciso IV do dispositivo acima mencionado prevê a possibilidade de contratação direta nos casos de emergência ou de calamidade pública, desde que caracterizada urgência de atendimento de situação que possa ocasionar prejuízo ou comprometer a segurança de pessoas, obras, serviços, equipamentos e outros bens públicos ou particulares:

\begin{abstract}
Art. 24. É dispensável a licitação:
$[\ldots]$

IV - nos casos de emergência ou de calamidade pública, quando caracterizada urgência de atendimento de situação que possa ocasionar prejuízo ou comprometer a segurança de pessoas, obras, serviços, equipamentos e outros bens, públicos ou particulares, e somente para os bens necessários ao atendimento da situação emergencial ou calamitosa e para as parcelas de obras e serviços que possam ser concluídas no prazo máximo de 180 (cento e oitenta) dias consecutivos e ininterruptos, contados da ocorrência da emergência ou calamidade, vedada a prorrogação dos respectivos contratos;
\end{abstract}

Esta excepcionalidade fundamenta-se na incompatibilidade do procedimento licitatório ordinário frente a situações urgentes, que demandam uma atuação célere por parte do agente administrativo para tutelar o interesse público envolvido na questão.

Ocorre que, em diversos momentos, a citada hipótese serve ao descompasso da atuação administrativa, em flagrante violação do interesse público e afronta às normas legais e constitucionais que versam sobre o tema.

É notório, ressalta-se, a existência de casos de contratação direta com fundamento em situações emergenciais ou de calamidade pública que não só suportariam, mas deveriam ter sido realizados através de procedimento licitatório prévio, seja em razão da inocorrência fática de tais situações, seja decorrente da inércia da própria administração pública no exercício de suas atribuições. 
Para além desta questão, da leitura do dispositivo anteriormente citado, depreende-se a existência de diversos limites importantes para determinar a aplicação da regra, a exemplo da definição do objeto da contratação, do prazo para conclusão das obras e da vedação de prorrogação contratual.

Tais disposições, por vezes, também são desrespeitadas pela Administração Pública, incrementando o imbróglio pendente sobre a aplicação do texto normativo em comento.

De outra banda, deve-se salientar que existem situações que não se enquadram perfeitamente na regra sob análise, mas que demandam a dispensa da licitação para tutelar com a maior efetividade possível o interesse público envolvido no caso concreto, finalidade primordial da Administração Pública.

Obviamente que tais hipóteses necessitam de tratamento específico e são capazes de, até mesmo, a depender do caso, superar os limites contidos expressamente no dispositivo em questão.

Daí as razões que tornam relevante a análise da regra contida no artigo 24, inciso IV, da Lei $n^{\circ} 8.666 / 1993$.

Sob este cenário, o presente trabalho terá por escopo central o exame do dispositivo acima mencionado, a fim de definir, de modo objetivo e fundamentado, os critérios legitimadores de sua interpretação e aplicação, bem como fixar os seus limites e as respectivas superações legais.

Para tanto, em um primeiro momento, serão abordados os aspectos gerais e fundamentais do instituto da licitação, ocasião em que se apresentará o seu histórico, natureza jurídica, disciplina normativa, finalidades, fundamentos e pressupostos, bem como a ideia relativa ao seu caráter principiológico de índole constitucional e respectivo conceito. 
$\mathrm{Na}$ sequência, a análise dirigir-se-á às contratações diretas, sem a realização do procedimento ordinário de licitação. Neste momento, após a demonstração das noções gerais que permeiam a contratação em si, o exame recairá sobre a definição de suas espécies e a correspondente formalização dos ajustes. Tudo com o objetivo de delimitar o tema em suas razões fundamentais e conferir supedâneo para a investigação do objeto central do trabalho.

A partir do quarto capítulo, adentrar-se-á ao ponto fulcral da pesquisa, oportunidade em que se analisará especificamente a regra contida no inciso IV, do artigo 24 , da Lei ${ }^{\circ}$ $8.666 / 1993$.

De início, tecer-se-á considerações gerais sobre o instituto, necessárias à sua compreensão.

Ato seguinte, a investigação incidirá sobre os pressupostos de validade para se efetivar a contratação direta com base na regra acima disposta, ocasião em que serão examinados, de forma específica, o conceito de "calamidade pública" e "emergência", inclusive com a análise de seus desdobramentos diante de situações peculiares, como o caso da "emergência fabricada" e da emergência causada por obstrução judicial e também pelo contingenciamento de repasses de recursos, bem como a urgência de atendimento ao risco iminente de dano e a correspondente adequação do objeto contratual.

Superado este tópico, serão abordados os limites contratuais decorrentes da regra em comento, com exame das restrições que recaem sobre o objeto e sobre a vigência da contratação, inclusive com a averiguação de suas respectivas superações.

Ao final do capítulo, o estudo se debruçará sobre a flexibilização do procedimento referente à formalização destas contratações, com exame exclusivo sobre a possibilidade de se realizar um projeto básico simplificado e de se efetuar um ajuste verbal.

O quinto capítulo do trabalho, por último, será destinado a relacionar as superações legais apresentadas no curso da pesquisa com princípios legitimadores de sua intepretação e 
aplicação.

Deste modo, após delimitar a correlação que será realizada e apresentar noções conceituais básicas sobre tema, o exame terá como objeto a análise dos princípios da legalidade, finalidade, obrigatoriedade de desempenho da atividade pública, eficiência e razoabilidade, sempre com foco na interpretação e aplicação das superações legais suscitadas no âmbito do presente estudo.

Cumpre esclarecer que o trabalho se efetivará com base na doutrina especializada no tema e com fundamento no exame jurisprudencial das questões aventadas no estudo, com foco principal nos julgados proferidos pelo Tribunal de Contas da União, órgão técnicoadministrativo que avalia a matéria no âmbito federal e possui, além de uma estrutura capaz de viabilizar a pesquisa em questão, representatividade nacional, porquanto aprecia as contratações realizadas com recursos federais pelos diversos entes federativos, em todas as regiões do país.

Vale ressaltar, por derradeiro, que o presente trabalho não servirá à apreciação da semelhante regra contida no artigo 29, inciso XV, da Lei $n^{\circ} 13.303 / 2016$, que dispõe sobre o estatuto jurídico da empresa pública e da sociedade de economia mista e suas subsidiárias no âmbito da União, dos Estados, do Distrito Federal e dos Municípios, uma vez que se trata de norma específica, que merece ser analisada em estudo próprio, não condizente com o escopo desta pesquisa. 


\section{6 - CONCLUSÕES}

O instituto da licitação encontra-se presente no ordenamento jurídico aplicável ao âmbito nacional desde longa data, inicialmente sem muitas formalidades, mas sempre com o objetivo primordial de conferir à Administração Pública a melhor contratação.

Com o transcorrer do tempo, sua regulamentação adquiriu forma e, após a disposição em alguns diplomas normativos, alcançou fundamento de ordem suprema com o advento da Constituição Federal de 1988. A partir de então, o instituto consolidou-se como regra constitucional a ser observada por todos os entes federativos por ocasião das contratações relativas a obras, serviços, compras e alienações, ressalvando-se apenas os casos especificados em lei.

O referido avanço também pacificou - de certo modo - a noção em torno da competência legislativa para tratar do instituto. Fixou-se, sem maiores dúvidas, à União competência privativa para legislar normas gerais de licitação e contratação, em todas as modalidades, para as administrações púbicas diretas e indiretas de todos os entes que compõem a federação.

No uso desta competência privativa, a União editou a Lei $\mathrm{n}^{\circ}$ 8.666/1993, que estabelece normas gerais sobre licitações e contratos administrativos pertinentes a obras, serviços, inclusive de publicidade, compras, alienações e locações no âmbito dos Poderes da União, dos Estados, do Distrito Federal e dos Municípios.

Citada norma, verdadeiro estatuto das licitações e contratos, trouxe ao cenário legislativo as exceções ao procedimento licitatório, dentre as quais se destaca a dispensa de licitação fundamentada em situações emergenciais ou de calamidade pública prevista em seu artigo 24, inciso IV.

Vale ressaltar que, juntamente com essas exceções, a lei em comento também 
apresentou o procedimento formal a ser seguido por ocasião da realização de contratações diretas, com certos temperamentos, mas com capacidade de indicar que se selecionou a proposta mais vantajosa possível para a Administração Pública, não havendo qualquer liberdade desmedida ou imotivada de atuação por parte do agente público.

Especificamente sobre a hipótese de contratação direta objeto do presente trabalho, pode-se concluir que a sua razão de existir situa na incompatibilidade que subsiste entre o tempo necessário à realização do procedimento ordinário de licitação e a necessidade de atuação imediata diante de uma situação emergencial ou calamitosa que possa ocasionar prejuízo ou comprometer a segurança de pessoas, obras, serviços, equipamentos e outros bens, públicos ou particulares.

O tempo existente para agir com o objetivo de eliminar o risco de dano irreparável, portanto, revela-se como verdadeira pedra angular destas contratações, razão pela qual deve ser considerado em qualquer interpretação e aplicação da regra, inclusive no âmbito dos limites legais que recaem sobre os contratos celebrados com fundamento no dispositivo em questão e no correspondente procedimento de formalização.

A análise da doutrina especializada e da jurisprudência técnica que tratam sobre o tema demonstra que ambas adotam como premissa de suas conclusões esta linha de entendimento, inclusive para subsidiar posições extremas, de caráter excepcionais, que superam a literalidade do dispositivo sob exame.

Buscam amparo também nos princípios jurídicos que se dirigem à atividade administrativa, em especial nos princípios da finalidade, da obrigatoriedade de desempenho da atividade pública, da eficiência e da razoabilidade, o que denota a aplicação de uma interpretação sistemática e teleológica em detrimento da exclusiva literalidade da regra que dispõe sobre a dispensa de licitação em comento.

Diante destas considerações, é possível apresentar, de modo objetivo, as conclusão que seguirão nos parágrafos subsequentes sobre a regra contida no inciso IV, do artigo 24 , da 
Lei $n^{0} 8.666 / 1993$.

Para que a contratação direta seja válida é necessário que estejam presentes cumulativamente os seguintes pressupostos: a) situação emergencial ou de calamidade pública; b) urgência de atendimento a um risco iminente de dano a pessoas, obras, serviços, equipamentos e outros bens, públicos ou privados; e, por fim, c) objeto contratual adequado.

O conceito de calamidade pública que suporta a contratação direta refere-se a tragédias inevitáveis, de grandes proporções, que comprometam substancialmente a capacidade de resposta do Poder Público do ente afetado para normalizar a situação, capaz de gerar dano ou prejuízo.

O estado de calamidade pública deve ser declarado por decreto do chefe do Poder Executivo, cuja redação deve fixar a área atingida e indicar as medidas que serão adotadas pelas autoridades competentes, evitando a denominada "indústria de calamidade pública".

Emergência para fins da aplicação do dispositivo refere-se à ocorrência efetiva de uma situação anormal, além do padrão tido pelo Poder Público de um determinado local e que afete a sua capacidade de resposta de modo parcial, devendo receber imediato tratamento, sob pena de afetar negativamente os interesses coletivos envolvidos no caso.

Para caracterizá-la, não é necessária a realização de um ato formal, bastando que a autoridade competente pela atuação imprescindível declare fundamentadamente suas razões por ocasião da dispensa de licitação.

A hipótese denominada "emergência fabricada" refere-se à situação anormal, de caráter negativo, criada pela própria Administração Pública, em razão de sua inércia ou má gestão no trato dos interesses públicos. Sua ocorrência autoriza a dispensa de licitação, mas impõe que seja apurada a responsabilidade do sujeito de que lhe deu causa.

A paralização do procedimento ordinário de licitação em razão de uma decisão 
judicial caracteriza emergência para fins da hipótese normativa em questão, podendo ser realizada a contratação direita, desde que não frustre a eficácia do provimento jurisdicional e estejam presentes os demais pressupostos necessários à dispensa de licitação.

Presentes os demais requisitos, o contingenciamento de repasses de recursos que possuem um prazo máximo para a sua utilização pode servir à caracterização de uma situação emergencial, porquanto a lei não faz diferença quanto à origem da situação excepcional. Da mesma forma que na "emergência fabricada", deve-se apurar a responsabilidade dos sujeitos que, sem justo motivo, deram causa ao atraso.

A urgência que deve estar presente nas situações anormais deve demandar uma atuação imediata por parte do Poder Público, incompatível com o procedimento ordinário de licitação, sob pena de ocorrência de danos concretos e irreparáveis a pessoas, obras, serviços, equipamentos e outros bens, públicos ou particulares.

O objeto contratual, por último, deve ser capaz de efetivamente ilidir o risco que permeia a situação excepcional, sob pena da dispensa de licitação ser considerada irregular por parte dos órgãos de controle.

A norma prevê expressamente dois limites contratuais. Um relativo ao objeto e outro referente à vigência do contrato. Ambos, contudo, não merecem interpretações absolutas e estanques.

Com relação ao primeiro limite, a regra impõe que só é possível contratar com dispensa de licitação objeto que tenha relação direta com a situação anormal e que seja imprescindível à eliminação do iminente risco de dano dela decorrente. De forma excepcional, tanto a doutrina como a jurisprudência técnica admitem a possibilidade de que a contratação abranja soluções mais amplas, de caráter definitivo e completo, em homenagem ao princípio da eficiência e da razoabilidade.

Quanto à segunda restrição, o dispositivo prevê que somente é possível contratar de 
forma emergencial as parcelas de obras e serviços que possam ser concluídas no prazo máximo de 180 (cento e oitenta) dias consecutivos e ininterruptos, contados da ocorrência da emergência ou calamidade, vedada a prorrogação dos respectivos contratos.

Novamente, de forma excepcional, tanto a doutrina majoritária quanto a jurisprudência técnica admitem, conforme a realidade da situação anormal e em homenagem à tutela do interesse coletivo envolvido no caso concreto, verdadeira finalidade normativa da regra sob análise, que pode ser ultrapassado o limite de 180 (cento e oitenta) dias, desde que presentes os requisitos autorizadores da contratação direta em questão, seja por meio da prorrogação do contrato eventualmente existente, seja através da celebração de um novo contrato, a depender do juízo de conveniência da Administração Pública, realizado com base na economicidade e eficiência das ações necessárias à eliminação do risco de dano existente.

No que tange à formalização de tais contratações diretas, admite-se, também de maneira excepcional, certa flexibilização de seu procedimento nas hipóteses de atendimento a situações emergenciais ou de calamidade pública que possuam caráter gravíssimo, em que o tempo para ação configure elemento extraordinariamente reduzido. Nestas situações, pode a Administração Pública agir com base em um ajuste verbal ou com referência a um projeto básico simplificado, elaborado, inclusive, de modo concomitante à atuação do poder público.

A partir de uma análise sistemática e teleológica, pode-se concluir que as superações legais constatadas em razão de situações extremas, além da anormalidade que se espera de uma hipótese de emergência ou de calamidade pública, fundamentam-se no ordenamento jurídico como um todo, especialmente nos princípios da finalidade, da obrigatoriedade de desempenho da atividade pública, da eficiência e da razoabilidade.

Muito embora não se ajustem perfeitamente à literalidade de algumas regras contidas na Lei nº 8.666/1993, não devem ser entendidas como ilegais, já que o princípio da legalidade atual, tomado em sentido amplo, não se limita à mera subsunção do fato à regra posta. 


\section{7 - BIBLIOGRAFIA}

AMARAL, Antônio Carlos Cintra do. Dispensa de licitação por emergência. In: Revista Trimestral de Direito Público - RTDP, nº 1/186-191. São Paulo: Malheiros, 1993.

ARAÚJO, Edmir Netto de. Curso de Direito Administrativo. $7^{\text {a }}$ ed. São Paulo: Saraiva, 2015.

ÁVILA, Humberto. Teoria dos princípios: da definição à aplicação dos princípios jurídicos. $7^{\mathrm{a}}$ ed. São Paulo: Malheiros, 2007.

BARROSO, Luís Roberto, Curso de direito constitucional contemporâneo, $3^{\mathrm{a}}$ ed., São Paulo: Saraiva, 2012.

BAZILLI, Roberto Ribeiro; MIRANDA, Sandra Julien. Licitação à luz do direito positivo. São Paulo: Malheiros, 1999.

BRASIL, Superior Tribunal de Justiça. Recurso Ordinário em Mandado de Segurança $\mathbf{n}^{\circ}$ 16.536/PE. Sexta Turma. Ministro Relator Celso Limongi. Data do julgamento: 02/02/2010.

. Agravo Regimental na Suspensão de Segurança no 2.476/SE. Corte Especial. Ministro Relator Ari Pargendler. Data do Julgamento: 01/07/2011.

BRASIL, Supremo Tribunal Federal. Ação Direta de Inconstitucionalidade no 927 - Medida Cautelar. Tribunal Pleno, Ministro Relator Carlos Velloso, julgado em 03 de nov. 1993.

Ação Penal no 348/SC. Tribunal Pleno. Ministro Relator Eros Grau, julgado em 03 de ago. de 2007.

BRASIL, Tribunal de Contas da União. Processo n ${ }^{\circ}$ 926.268/1998-8, Ministro Relator Valmir 
Campelo. Decisão n 524/1999 - Plenário. Data da Sessão: 11/08/1999.

. Processo $\mathbf{n}^{\circ}$ 009.248/1994-3. Ministro Relator Carlos Átila Álvares da Silva. Decisão n 347/1994 - Plenário. Data da Sessão: 21/06/1994.

. Processo $\mathbf{n}^{\circ}$ 007.826/1994-0. Ministro Relator Adhemar Paladini Ghisi. Acórdão n 300/1995 - Segunda Câmara. Data da Sessão: 28/09/1995.

. Processo $n^{\circ}$ 007.825/1999-4. Ministro Relator Ubiratan Aguiar. Decisão $n^{\circ}$ 135/2001 - Segunda Câmara. Data da Sessão: 07/06/2001.

- Processo $\mathbf{n}^{\circ}$ 007.585/1999-7. Ministro Relator Walton Alencar Rodrigues. Decisão n 46/2002 - Plenário. Data da Sessão: 27/02/2002.

- Processo $n^{\circ}$ 016.224/2001-2. Ministro Relator Marcos Bemquerer Costa. Acórdão n 100/2003 - Plenário. Data da Sessão: 12/02/2003.

. Processo $n^{\circ}$ 005.457/20003-2. Ministro Relator Ubiratan Aguiar. Decisão $n^{\circ}$ 300/2004 - Plenário. Data da Sessão: 24/03/2004.

. Processo $\mathbf{n}^{\circ}$ 001.605/2005-5. Ministro Relator Augusto Sherman. Acórdão $\mathrm{n}^{\circ}$ 667/2005 - Plenário. Data da Sessão: 25/05/2005

. Processo $n^{\circ}$ 019.967/2005-4. Ministro Relator Ubiratan Aguiar. Acórdão $n^{\circ}$ 1.336/2006 - Plenário. Data da Sessão: 02/08/2006.

- Processo $\mathrm{n}^{\circ}$ 006.182/2005-0, Ministro Relator Ubiratan Aguiar. Acórdão $\mathrm{n}^{\circ}$ 1.889/2006 - Plenário. Data da Sessão: 11/10/2006.

- Processo $\mathrm{n}^{\circ}$ 005.457/2003-2, Ministro Relator Aroldo Cedraz. Acórdão $\mathrm{n}^{\circ}$ 403/2007 - Plenário. Data da Sessão: 21/03/2007. 
. Processo $\mathbf{n}^{\circ}$ 008.403/1999-6, Ministro Relator Aroldo Cedraz. Decisão $n^{\circ}$ 1876/2007 - Plenário. Data da Sessão: 12/09/2007.

. Processo $\mathbf{n}^{\circ}$ 005.236/2005-8. Ministro Relator Marcos Vinicios Vilaça. Acórdão n ${ }^{\circ}$ 1.020/2008 - Primeira Câmara. Sessão de 08/04/2008.

Processo ${ }^{\circ}$ 005.236/2005-8. Ministro Relator Marcos Vinicios Vilaça. Decisão $n^{\circ} 1.020 / 2008$ - Primeira Câmara. Data da Sessão: 28/04/2008.

. Processo $\mathrm{n}^{\circ}$ 010.760/2009-4. Ministro Relator Augusto Sherman. Acórdão $\mathrm{n}^{\circ}$ 1.901/2009 - Plenário. Data da Sessão: 26/08/2009.

. Processo ${ }^{\circ}$ 019.362/2010-2. Ministro Relator Benjamin Zymler. Acórdão $n^{\circ}$ 3.238/2010 - Plenário. Data da Sessão: 01/12/2010.

. Processo $n^{\circ}$ 025.812/2007-2. Ministro Relator Augusto Nardes. Acórdão $n^{\circ}$ 8.356/2010 - Primeira Câmara. Sessão de 07/12/2010

- Processo $n^{\circ}$ 006.567/2005-5. Ministro Relator Aroldo Cedraz. Acórdão $n^{\circ}$ 34/2011 - Plenário. Data da Sessão: 19/01/2011.

. Processo $\mathbf{n}^{\mathbf{0}}$ 020.159/2010-2. Ministro Relator Ubiratan Aguiar. Acórdão $\mathrm{n}^{\mathrm{o}}$ 106/2011 - Plenário. Data da Sessão: 26/01/2011.

. Processo $n^{\circ}$ 007.965/2008-1. Ministro Relator Valmir Campelo. Acórdão $n^{\circ}$ 943/2011 - Plenário. Data da Sessão: 13/04/2011.

- Processo $n^{\circ}$ 014.245/2011-6. Ministro Relator José Jorge. Acórdão $n^{\circ}$ 2.190/2011 - Plenário. Data da Sessão: 17/08/2011 
- Processo $\mathrm{n}^{\circ}$ 004.063/2008-4. Ministro Relator José Jorge. Acórdão $\mathrm{n}^{\circ}$ 1.162/2014 - Plenário. Data da Sessão: 07/05/2014.

. Processo n⿳0 032.583/2011-7. Ministro Relator José Múcio Monteiro. Acórdão no 1681/2015 - Primeira Câmara. Data da Sessão de 24/03/2015.

BITTENCOURT, Sidney. Contratando sem licitação. São Paulo: Almedina, 2016.

CAETANO, Marcello. Manual de Direito Administrativo. Vol. I.10 a ed. Coimbra: Livraria Almedina, 1997.

CARVAlHO FILHO, José dos Santos. Manual de direito administrativo. $28^{a}$ ed. São Paulo: Atlas, 2015.

CRETELla JR., José. Das licitações Públicas. 18ª ed. Rio de Janeiro: Forense, 2008.

CUNHA JÚNIOR, Dirley da. Curso de direito administrativo. $7^{\mathrm{a}}$ ed. Bahia: Juspodivm, 2009.

D`AVILA, Vera Lúcia Machado. Dispensa de licitação. Urgência ou emergência. Conceito. In: Temas polêmicos sobre licitações e contratos. $5^{\text {a }}$ ed. São Paulo: Malheiros, 2006, p. 110113.

DALLARI. Adilson Abreu. Dispensa de licitação por urgência. In: Revista Zênite Informativo de Licitações e Contratos (ILC), nº 69/852-857. Curitiba, nov/1999.

DI PIETRO, Maria Sylvia Zanella. Direito Administrativo. São Paulo: Atlas, 2015. . Dispensa de licitação. Urgência da contratação. Inércia do Servidor. In: Temas polêmicos sobre licitações e contratos. $5^{\mathrm{a}}$ ed. São Paulo: Malheiros, 2006, p. 109. 
FAGUNDES, Miguel Seabra. O controle dos atos administrativos pelo Poder Judiciário. $4^{\mathrm{a}}$ ed. Rio de Janeiro: Companhia Forense de Artes Gráficas, 1967.

FERNANDES, Jorge Ulisses Jacoby. Contratação direta sem licitação. $10^{\mathrm{a}}$ ed. Belo Horizonte: Fórum, 2016.

FIGUEIREDO, Lúcia Valle. Curso de direito administrativo. $6^{\text {a }}$ ed. São Paulo: Malheiros, 2003.

FIGUEIREDO, Lúcia Valle; FERRAZ, Sérgio. Dispensa e inexigibilidade de licitação. $3^{\mathrm{a}}$ ed. São Paulo: Malheiros, 1994.

FURTADO, Lucas Rocha. Curso de licitações e contratos administrativos. $7^{\mathrm{a}}$ ed. Belo Horizonte: Fórum, 2017.

GASPARINI, Diogenes. Direito administrativo. 17ª Ed. São Paulo: Saraiva, 2012.

GOMES, José Jarbas de Aguiar. Dispensa de Licitação. In: Ensaios de Cidadania 1: Licitações. TARIFA, José Benedito (coordenador). São Paulo: Ministério Público do Estado de São Paulo, 2005, p. 84-116.

JUSTEN FILHO, Marçal. Comentários à lei de licitações e contratos administrativos. São Paulo: Revista dos Tribunais, 2014.

. Curso de direito administrativo. São Paulo: Revista dos Tribunais, 2014.

MEDAUAR, Odete. Dispensa e inexigibilidade de licitação. In: MEDAUAR, Odete (organizador). Licitações e Contratos Administrativos. São Paulo: Nova Dimensão Jurídica, 1998, p. 33-59.

MEIRELLES, Hely Lopes. Direito administrativo brasileiro. $28^{\mathrm{a}}$ ed. São Paulo: Malheiros, 
2003.

Licitação e contrato administrativo. $15^{\mathrm{a}}$ ed. São Paulo: Malheiros, 2010.

MELlO, Celso Antônio Bandeira de. Criação de secretarias municipais: inconstitucionalidade do art. 43 da Lei Orgânica dos Municípios do Estado de São Paulo. In: Revista de Direito Público - RDP, n. 15. São Paulo, jan./mar. 1971.

. Curso de Direito Administrativo. 32ª ed. São Paulo: Malheiros, 2015.

MOREIRA NETO, Diogo de Figueiredo. Competência concorrente limitada - o problema da conceituação das normas gerais. Revista de Informação Legislativa n. 100, out./dez, 1988.

Curso de direito administrativo. $16^{\text {a }}$ ed. Rio de Janeiro: Forense, 2014.

MUKAI, Toshio. Estatutos jurídicos de licitações e contratos administrativos. $3^{\mathrm{a}}$ ed. São Paulo: Saraiva, 1992.

NIEBUHR, Joel de Menezes. Dispensa e inexigibilidade de licitação pública. $4^{\mathrm{a}}$ ed. Belo Horizonte: Fórum, 2015.

NOHARA, Irene Patrícia. Direito Administrativo. $7^{\text {a }}$ ed. São Paulo: Atlas, 2017.

OLIVEIRA, José Roberto Pimenta de. Os princípios da razoabilidade e da proporcionalidade no direito administrativo brasileiro. São Paulo: Malheiros, 2006.

PEREIRA JR., Jessé Torres. Comentários à lei das licitações e contratações da Administração Pública. 8 ed., Rio de Janeiro: Renovar, 2009.

PRESIDÊNCIA DA REPÚBLICA. Plano Diretor da Reforma do Aparelho do Estado. 
Brasília. 1995, p. 21. Disponível em: <http://www.biblioteca.presidencia.gov.br/publicacoesoficiais/catalogo/fhc/plano-diretor-da-reforma-do-aparelho-do-estado-1995.pdf $>$ Acesso em: 12 de dez. de 2018.

RAMOS, Saulo. Licitação - Decreto-lei no 2.300 - Exposição de motivos. Revista de Direito Administrativo - RDA, v. 166, 1986, p. 174. Disponível em: $<$ http://bibliotecadigital.fgv.br/ojs/index.php/rda/article/view/45345/43832> Acesso em: 06 de dez. de 2018.

RIGOLIN, Ivan Barbosa; BOTTINO, Marco Tullio. Manual prático das licitações. $8^{\mathrm{a}}$ ed. São Paulo: Saraiva, 2009.

ROCHA, Carmén Lúcia Antunes Rocha. Conceito de urgência no direito público brasileiro. In: Revista Trimestral de Direito Público - RTDP, nº 01. São Paulo: Malheiros, 1993.

ROSILHO, André. Licitações no Brasil. São Paulo: Malheiros, 2013.

SARLET, Ingo Wolfgang. Curso de Direito Constitucional, São Paulo: Saraiva, 2015.

SOGAYAR, Alberto Sanz. A questão relativa à vigência contratual no tocante à contratação sem licitação decorrente de emergência ou calamidade pública. In: Revista Zênite - Informativo de Licitações e Contratos (ILC), nº 36/100-102. Curitiba, fev./1997.

SUNDFELD, Carlos Ari. Fundamentos de direito público. $4^{\mathrm{a}}$ ed., São Paulo: Malheiros, 2001.

Licitação e Contrato Administrativo. $2^{\mathrm{a}}$ ed. São Paulo: Malheiros, 1995.

TANAKA, Sônia Yuriko. Dispensa e inexigibilidade de licitação. In: Estudos sobre licitações e contratos. GARCIA, Maria (coord.). Rio de Janeiro: Forense Universitária, p. 1761. 
TELLES, Antônio A. Queiroz. Introdução ao direito administrativo. 2a ed. São Paulo: Revista dos Tribunais, 2000.

UNIVERSIDADE DE COIMBRA. Ordenações Filipinas. Disponível em: <http://www1.ci.uc.pt/ihti/proj/filipinas/11p151.htm > Acesso em: 29 nov. 2018.

ZENITE, Consultoria. A atenuação do limite de 180 dias de duração dos contratos por emergências. In: Revista Zênite - Informativo de Licitações e Contratos (ILC), nº 82/10101013. Curitiba, dez./2000. 